\title{
OS SUJEITOS DO PROEJA: A PARTICIPAÇÃO DA MULHER NO CURSO TÉCNICO INTEGRADO DE SEGURANÇA DO TRABALHO NO IFES - CAMPUS VITÓRIA
}

\author{
ICLÉIA BARBosa MARINHO ${ }^{1}$, MARIA JOSÉ DE RESENDE FERREIRA ${ }^{2}$ \\ Pós-graduação Lato Sensu em PROEJA, Instituto Federal do Espírito Santo \\ E-mail: icleiabmarinho@gmail.com, majoresende@yahoo.com.br
}

\section{RESUMO}

Esse artigo é um recorte do trabalho monográfico apresentado para a conclusão do Curso de Pós-Graduação Lato Senso em Educação Profissional e Técnica Integrada à Educação Básica na Modalidade de Educação de Jovens e Adultos do Instituto Federal de Educação do Espírito Santo. Objetiva analisar a participação da mulher no Curso Técnico Integrado de Segurança do Trabalho do Instituto Federal do Espírito Santo Campus Vitória. Empreendeu-se uma pesquisa qualitativa, de cunho exploratório, com apresentação de estudo de caso. Foi utilizada para a produção dos dados a entrevista semi-estruturada aplicadas a oito (8) alunas, do 8ㅇ (oitavo) módulo do curso. Constatou-se que gradativamente, as mulheres estão vencendo barreiras e buscando inserirse no mercado de trabalho, em profissão que até pouco tempo era reduto masculino: atividades na área industrial. Também se averiguou que enfrentam condições adversas no seu cotidiano, persistindo ainda a desigualdade sexista nas relações escolares e familiares, que se traduzem ainda na subordinação da mulher ao homem. Foi comprovado, que as mesmas enfrentam dificuldades, em relação à família para estudarem e exercerem sua profissão, causadas pelo preconceito e por não terem assistência pública de apoio à infância.

Palavras-chaves: Escolarização. Gênero. Educação de Jovens e Adultos. PROEJA.

\section{INTRODUÇÃO}

As exigências do novo modelo societário ocorrido nos últimos anos, principalmente a econômica, forçaram muitas mulheres a buscar o aumento do seu grau de escolaridade, para uma melhor inserção no mercado de trabalho e para conquistar os direitos básicos para o exercício da cidadania.

Apesar das conquistas obtidas nas últimas décadas, ainda existem muitos desafios para que o gênero feminino viva uma situação de real igualdade, no que diz respeito ao acesso a escolarização, ao emprego formal e remunerado, ao salário digno e a ascensão a cargos no trabalho ${ }^{3}$.

Os estudos sobre gênero e escolarização feminina apontam que processo de exclusão das mulheres das camadas populares, do ambiente escolar, deve-se, principalmente, por estas assumirem desde cedo, obrigações domésticas ou por buscarem meios de sustento da família, desempenhando atividades das mais diversas ordens no mercado de trabalho, no emprego doméstico, em subempregos ou outras atividades informais.

Atualmente, cresce o contingente de frequentadores da Educação de Jovens e Adultos (EJA) e, deste público, destacamos a presença das mulheres inserida neste contexto (BRASIL, 2007). Na percepção de Menezes (2005), a EJA nas últimas décadas está se configurando num espaço onde se tem buscado, paulatinamente, superar a exclusão das mulheres do sistema escolar.

Dentre as ofertas de escolarização para o público oriundo da EJA, destaca-se o Programa de Integração da Educação Profissional à Educação Básica na Modalidade de Educação de Jovens e Adultos (PROEJA), que tem como objetivo articular a Educação Básica, a Educação de Jovens e Adultos e a Educação Profissional, com vistas à elevação da escolaridade via profissionalização.

\footnotetext{
${ }^{1}$ Especialista em Educação Profissional na modalidade EJA. Pedagoga Especialista em Gestão e Educação Ambiental. Pós Graduada pelas Faculdades Associadas do Espírito Santo - FAESA. Professora de Filosofia da rede estadual do ES.

${ }^{2}$ Mestre em Educação. Coordenadora do PROEJA Ifes Campus Vitória e Professora da Pós- PROEJA e das Licenciaturas em Química, Letras e Informática. Membro do Grupo de Pesquisa PROEJA/CAPES/SETEC-ES.

${ }^{3}$ No Estado do Espírito Santo, 20\% das mulheres ganha entre um e dois salários mínimos (de $R \$ 510$ a $R \$ 1.020$ ) e, entre as economicamente ativas, que representam 56\% do total, a maioria está na faixa etária entre 30 e 39 anos (GOUVÊA, 2010, p.29).
} 
Nesse sentido, investigar a participação da mulher no Curso Técnico Integrado de Segurança do Trabalho no Instituto Federal do Espírito Santo (Ifes) Campus Vitória ${ }^{4}$ vem contribuir para a visibilidade do Programa e para com a discussão das relações de gênero, em especial na EJA e na Educação Profissional Técnica (EPT).

De acordo com Pereira e Miguel (2008), ser mulher era, por muitas vezes, estar confinada ao mundo doméstico, no âmbito do espaço privado. Desse modo, representações se consolidaram no imaginário social e transformaram homens e mulheres em seres dicotômicos e privados de atitudes e/ou palavras que representassem uma divergência no papel "dito natural e correto a ser seguido".

Desta forma, pode-se verificar que, ao longo da história das mulheres, o termo gênero surgiu como forma de decodificar as relações entre homens e mulheres e dar significação às relações de poder. Conforme Pereira (1996, p.25):

Isto significa que o ser e o estar no mundo como homem ou mulher não é algo apenas natural e biologicamente determinado, mas, também, pertence à ordem do social e do cultural e, assim sendo, tais papéis se alteram no decorrer do processo histórico e também em função de outras determinações sociais como a classe e a raça. Tais categorias não se encontram separadas no contexto das diversas formações sociais, mas profundamente entrelaçadas entre si. Na educação, também, essas categorias se encontram em estreita articulação [...].

De acordo com Scott (1992, apud FERREIRA, 2007), o termo - gênero - foi utilizado primeiramente pelas feministas americanas com o sentido de evidenciar o aspecto social das distinções baseadas no sexo, como também para a rejeição no uso dos termos "sexos" ou "diferença sexual" com base no determinismo biológico.

Para Sponchiado (1997), muito do que se aprende e se ensina sobre ser mulher e ser homem é condizente com a afirmação de uma identidade (feminina ou masculina) em oposição a algo que seria próprio do outro sexo.

Segundo Beauvoir (1980, apud FERREIRA, 2007, p. 66), ninguém nasce mulher, torna-se mulher, assim, podemos afirmar que os seres - homens e mulheres - vão se formando pelos condicionamentos biológicos, psicológicos, e sócio-culturais. Essas relações sociais, construídas ao longo da história, dispõem como devem se comportar homens e mulheres nos papéis sociais atribuídos a cada um.

Nesse sentido, Louro (1997) afirma também que entender o gênero como constituinte da identidade dos sujeitos significa compreender os sujeitos como tendo identidades múltiplas, plurais, que se transformam, que não são fixas nem permanentes e que podem, até mesmo, ser contraditórias. Contudo, ao instituir a identidade do sujeito, assim como a etnia, a classe, o sexo, a nacionalidade, o gênero ultrapassa o mero desempenho de papéis, uma vez que faz parte do sujeito e o constitui.

Pode-se observar que as famílias educam seus filhos e filhas para se portarem conforme o que a sociedade determina como natural de mulher ou de homem. Então, os modelos atribuídos aos homens e as mulheres favorecem uma divisão sexual de trabalho, pois o modo de produção vivido pelo homem interfere no modo de se comportar e agir perante a sociedade.

De acordo com Ridenti (1998), o gênero masculino é definido pelo sucesso profissional, consolidando o homem principal provedor do sustento familiar. Já a mulher, mesmo que possua também um sucesso profissional, seu status ainda se encontra marcado pelo sucesso em articular a vida familiar com o trabalho, uma vez que a aceitação do trabalho da mulher não a dispensa de ser responsável pelas tarefas da casa e dos cuidados com os filhos, marido, idosos ou familiares doentes.

A autora ainda afirma que a inserção da mulher no mercado de trabalho não diminuiu suas tarefas com o trabalho doméstico e familiar, nem a desigualdade entre homens e mulheres com relação às oportunidades de trabalho, à questão salarial, à ocupação de cargos, etc. Entretanto, a autora reconhece que "favoreceu alguma participação masculina na esfera doméstica e no cuidado com os filhos, alterando os arranjos domésticos e instituindo outras formas de relação entre homens e mulheres e entre adultos e crianças" (RIDENTI, 1998, p.167).

Isto confirma que,

\footnotetext{
${ }^{4}$ No Ifes Campus Vitória, o atendimento para esse público iniciou-se no ano de 2001, período regulado pelo Decreto no 2.208/97, com oferta do Ensino Médio para Jovens e Adultos Trabalhadores (EMJAT) e a partir de 2006, passa a ser nomeado como PROEJA e amplia seu atendimento aos sujeitos da EJA, ofertando a esse público, 03 de seus cursos técnicos profissionalizantes: Metalurgia e Materiais, Segurança do Trabalho e Edificações (FERREIRA; RAGGI; RESENDE, 2007).
} 
[...] por tradição histórica, a mulher teve sua existência atrelada à família, o que lhe dava a obrigação de submeter-se ao domínio masculino, seja pai, esposo ou mesmo o irmão. Sua identidade, segundo esses estudos, foi sendo construída em torno do casamento, da maternidade, da vida privada-doméstica, fora dos muros dos espaços públicos. E por essa tradição, construída historicamente, a mulher se viu destituída de seus direitos civis. Não podia participar de uma educação que fosse capaz de prepará-la para poder administrar sua própria vida e de ter acesso às profissões de maior prestígio. Assim, por um longo período histórico, a família, a igreja e a escola, elementos inerentes a esse processo, enquanto instituições, vão sustentar esse projeto moralizador, tutelando a mulher ao poder econômico e político do homem brasileiro (FERREIRA, 2008, p. 15).

\section{Percurso Metodológico}

Mediante aos objetivos propostos, optou-se em realizar uma pesquisa de natureza qualitativa, do tipo exploratória, com apresentação de estudo de caso. Foi utilizada para a produção dos dados a entrevista semiestruturada aplicadas a oito (8) alunas, do 8o (oitavo) módulo do curso Técnico Integrado de Segurança do Trabalho com 13 questões abertas. O lócus da pesquisa foi o Ifes Campus Vitória e a investigação foi realizada durante todo o mês de agosto e setembro de 2010 pela própria pesquisadora com o auxílio da Coordenadoria e do Setor pedagógico do PROEJA.

\section{RESULTADOS E DISCUSSÃo}

\section{APRESENTANDO AS ALUNAS}

Pelas entrevistas realizadas e pelos estudos feitos por Oliveira, Cezarino e Santos (2009, p. 7), percebese no Ifes Campus Vitória

a existência de dois grupos distintos de alunos: o primeiro grupo formado por sujeitos da EJA, trabalhadores, desempregados ou subempregados com histórico de descontinuidade escolar, dentre outras marcas sócio-culturais; e o segundo composto por estudantes, que concluíram o ensino médio e não possuem trajetórias irregulares no processo de escolarização.

A faixa etária das alunas entrevistadas está em torno dos 22 a 47 anos. É predominante as mulheres mais jovens com menos de 35 anos (Gráfico 1).

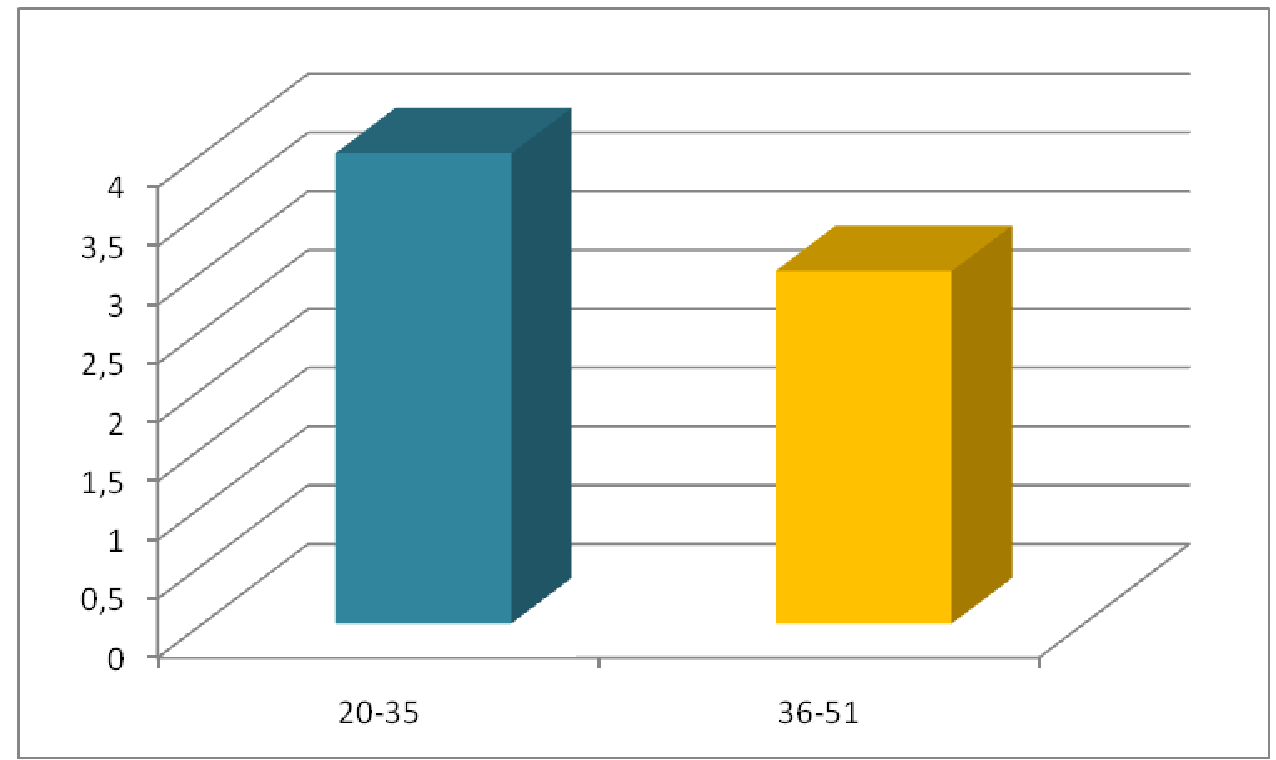

Gráfico 1 - Faixa etária das estudantes. 
Em 2009, segundo dados do Instituto Brasileiro de Geografia e Estatística (IBGE, 2010) 2,1 milhões de pessoas maiores de 15 anos de idade estavam matriculadas em cursos de educação de jovens e adultos. Nesse grupo, a maioria tem entre 25 e 39 anos (35,8\%). Os mais velhos (com 60 anos ou mais) são minoria nessa modalidade de ensino correspondendo a apenas $6,2 \%$.

Isso demonstra que a juvenilização da EJA, assim como do PROEJA, já é uma realidade. Essa questão também é retratada no Documento Base do PROEJA (2007), que denuncia: "um agravante na situação brasileira diz respeito à presença forte de jovens na EJA, em grande parte devido a problemas de não permanência e insucesso no ensino fundamental "regular"” (BRASIL, 2007, p. 10).

Questionadas quanto ao estado civil (Gráfico 2), 50\% delas declararam-se solteiras, 37,5\% casadas e $12,5 \%$ separadas judicialmente.

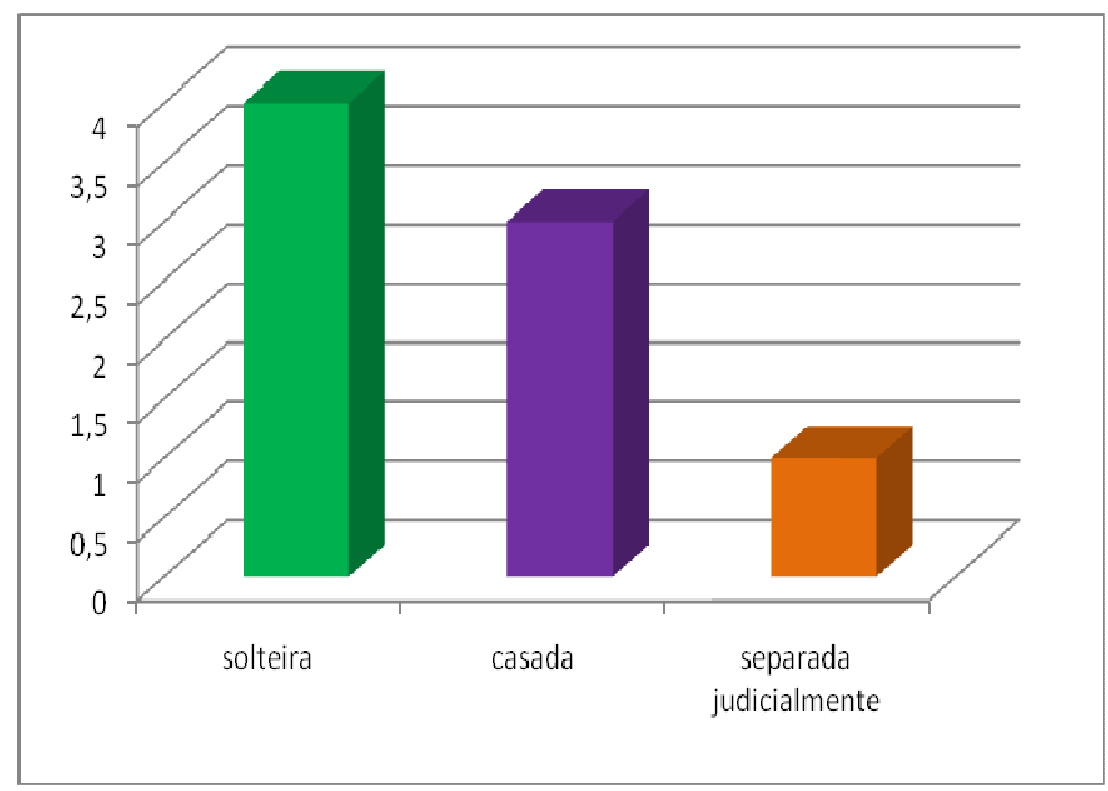

Gráfico 2 - Estado civil das alunas entrevistadas.

A maioria das alunas possuem até 2 (dois) filhos e/ou nenhum, como pode ser verificado no Gráfico 3. Seguindo a tendência de queda da fecundidade no país, as mulheres jovens estão tendo menos filhos. Em 1998, 7,6\% das adolescentes de 15 a 17 anos já tinham filhos, e em 2008 o percentual caiu para 6,3\% (IBGE, 2010, p. 141).

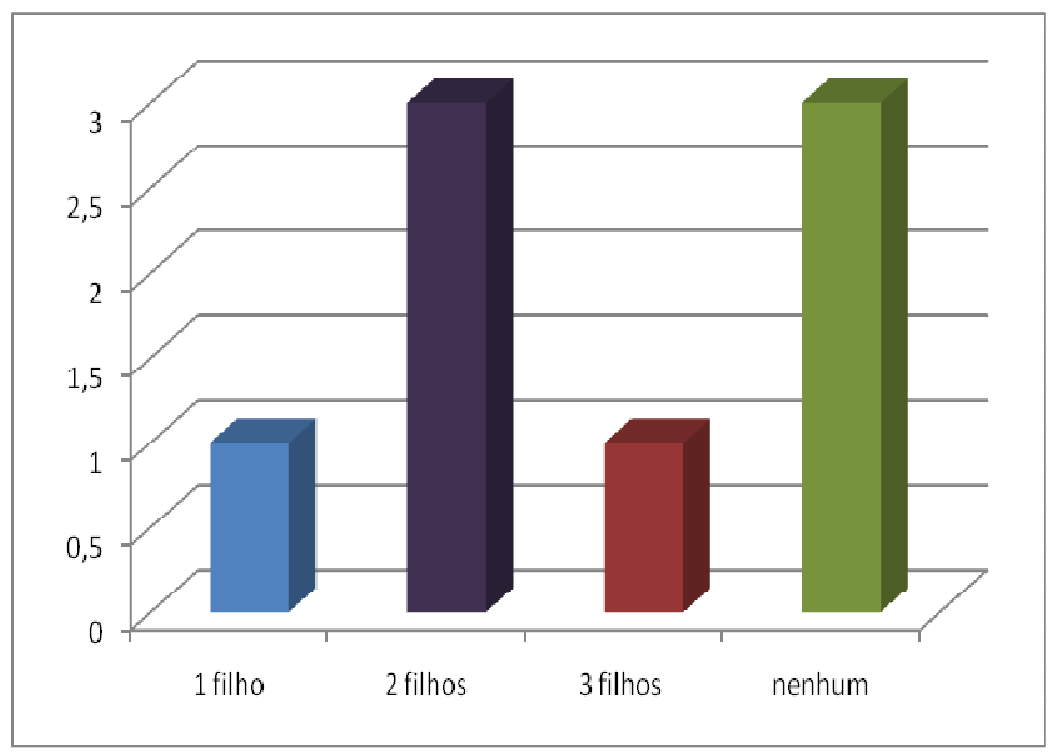

Gráfico 3 - Número de filhos. 
Grande parte das alunas encontram-se fora do mercado de trabalho, como pode ser constatado no gráfico 4.

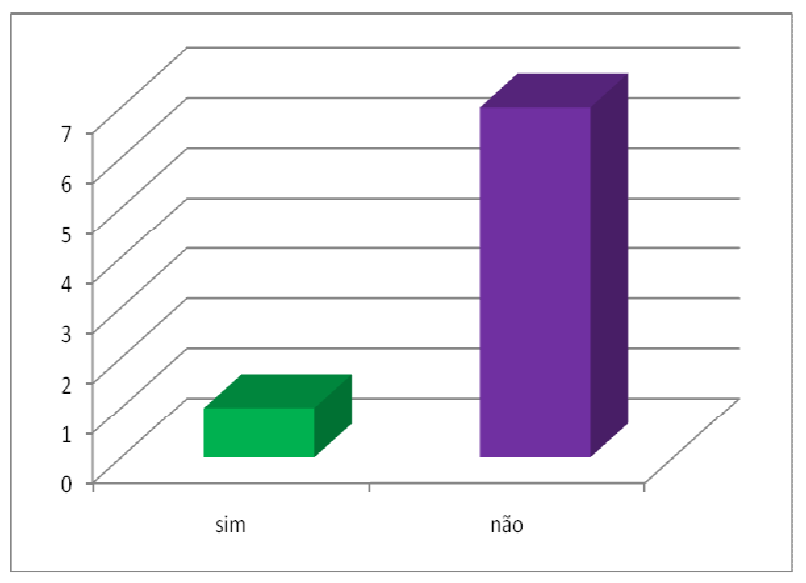

Gráfico 4 - Alunas que exercem atividade remunerada.

Apesar da maioria das alunas entrevistadas não possuírem uma ocupação fora de casa, segundo dados da Pesquisa Nacional por Amostras de Domicílio (PNAD - 1998/2008) divulgado pelo IBGE (2010), a taxa de ocupação das mulheres aumentou em todos os outros grupos etários analisados. Este aumento é, sem dúvida, fruto não só da necessidade de complementação da renda familiar, mas também resultado de uma maior independência cultural conquistada pela por esse público nas últimas décadas.

O IBGE (2010), por meio da Síntese de Indicadores Sociais (SIS), também divulgou que:

\begin{abstract}
Apesar do aumento da taxa de atividade das mulheres, essas permanecem como as principais responsáveis pelas atividades domésticas e cuidados com os filhos e demais familiares. No Brasil, a média de horas gastas pelas mulheres a partir dos 16 anos de idade em afazeres domésticos é mais do que o dobro da média de horas dos homens. Em 2009, enquanto as mulheres de 16 anos ou mais de idade ocupadas gastavam em média 22,0 horas em afazeres domésticos, os homens nessas mesmas condições gastavam, em média, 9,5 horas. [...]. A questão dos afazeres domésticos vista pela escolaridade mostra que as mulheres ocupadas com 12 anos ou mais de estudo passavam menos tempo se dedicando aos afazeres domésticos (17,0 horas semanais), quando comparadas às mulheres com até 8 anos de estudo (25,3 horas semanais) (IBGE, 2010).
\end{abstract}

Nesse sentido, as mulheres são "as principais responsáveis pelos cuidados com o espaço doméstico e familiar e são, portanto, elas as mais sobrecarregadas quando saem de casa para uma atividade remunerada" (BRUSCHINI E RICOLD, 2008, p.9). Ainda segundo as autoras.

Apesar do considerável volume de atividades que se escondem sob a rubrica "afazeres domésticos" e que mantêm ocupadas mulheres de todas as camadas sociais, o trabalho doméstico não é contabilizado como atividade econômica nesse tipo de levantamento (2008, p. 67).

\title{
SOBRE A IDENTIDADE FEMININA
}

Sabe-se que a de identidade feminina foi construída ao longo da história atrelada ao poder masculino e mesmo quando a mulher assumiu um novo papel social e profissional, devido ao aumento de sua escolarização e a sua ocupação em diversas profissões e em, inclusive, em áreas de trabalho consideradas "redutos masculinos", essa identidade ainda está marcada pela maternidade, a função de mãe, - construtos associado à identidade feminina (ALVES, 2006, apud FERREIRA, 2007, p 62):

Ao analisar os relatos das alunas sobre a compreensão da identidade feminina, percebe-se ainda, uma visão predominante do papel social da mulher como: mãe, esposa, filha, dona-de-casa e atualmente, trabalhadora e ainda um "ser frágil". Como pode ser observado no relato da aluna 1:

Ser mulher é ser autosuficiente e tão dependente ao mesmo tempo. É ser forte e corajosa, frágil e medrosa, tudo isso dependendo da situação. Afinal ser mulher é acima de tudo, ser adaptável, pois a mulher tem uma sensibilidade incrível (ALUNA 1). 
A identidade feminina, portanto, "é construída nas inter-relações que se estabelecem no cotidiano de cada uma" (FERREIRA, 2007, p. 66). Essas inter-relações definirão os significados que cada pessoa adquiriu pelas experiências de vida.

Em relação à pergunta sobre quais as dificuldades enfrentam no seu dia a dia por ser mulher, 4 (quatro) alunas relatam que a maior dificuldade é enfrentar o preconceito masculino, por achar que elas não são capazes de realizar certas tarefas; outra dificuldade relatada é a falta de divisão das tarefas domésticas com o companheiro.

Os estudos que contemplam essa temática reconhecem que, no momento, o qual as mulheres passaram a ocupar o espaço das atividades profissionais fora do lar, isso acarretou acréscimo nas suas atividades, pois essa mudança não foi acompanhada de implementação de uma estrutura de assistência à infância, como escolas integrais e creches. O companheiro também não assumiu sua responsabilidade para o desempenho das atividades domésticas (FERREIRA, 2003).

Quanto aos aspectos positivos por ser mulher, as alunas apontam a capacidade de ser mãe, a generosidade, o carinho, maior sensibilidade, possuir habilidades de realizar várias coisas ao mesmo tempo. É perceptível a satisfação das alunas por serem mulheres e Ferreira (2007) afirma que:

Esse papel exercido de mulher/mãe/esposa, foi construído por várias gerações, numa ordem patriarcal predominante e que prevalece até hoje. A preocupação com a família e com os afazeres da casa retratam a permanência, na cultura popular, de resquícios de subalternidade que a mulher sofreu (e sofre) na sociedade brasileira por ter sido imposta a ela a esfera doméstica com todas as atribuições inerentes aos cuidados para a sobrevivência dos entes familiares (2007. p. 5).

\section{SOBRE A EDUCAÇÃO}

Nesta seção serão analisados os motivos as quais levaram as alunas a interromperem e retornarem aos seus estudos. Os relatos no que diz respeito aos motivos para abandonarem os estudos são diversos e as principais motivações são: família, gravidez, filhos e trabalho. De acordo com as educandas: "Na infância minha familia se mudava muito, às vezes para locais onde não havia escolas, aos 10 anos já na 4ạ série não quis mais lutar para estudar" (ALUNA 1); "Porque na época eu tinha 16 anos e engravidei" (ALUNA 2); "Precisava trabalhar" (ALUNA 5) e "Para criar meus filhos" (ALUNA 6).

É comum na sociedade brasileira que nas famílias das camadas populares, as crianças comecem a trabalhar muito cedo para complementar a renda familiar, e na maioria das vezes em postos de trabalhos precários e muitas não conseguem retornar à escola. Morgado (2001, apud NADER, 2001, p. 12) também aponta que

"a mulher, ao se casar, tem por obrigação não desejar algo mais do que ter a sua família. [...]. Ao se casar, a mulher recebe uma carga de responsabilidade e que, para conservar-se bem casada, deve promover uma mudança radical em seu comportamento".

Diante dessa realidade, aos poucos, os anseios de escolarização vão desaparecendo diante dos múltiplos papéis impostos pelo casamento, ou seja, doméstica, esposa e mãe, ressalta a pesquisadora.

Deve-se destacar que somente parte do público alvo dessa investigação possuí as marcas identidárias dos sujeitos da EJA (OLIVEIRA, CEZARINO E SANTOS, 2009), ou seja, uma outra parcela das entrevistadas não foram excluídas de todo do processo educacional, conseguiram terminar (com dificuldades, segundo depoimentos) a Educação Básica e retornam ao Ifes com vistas à uma oportunidade de profissionalização técnica. Porém, podemos afirmar, que de uma forma ou outra sofreram (e ainda sofrem) impedimentos que denominamos de determinações sociais de gênero (FERREIRA, 2008).

Os motivos que as levaram a voltar a estudar podem ser verificados nos depoimentos a seguir: " $A$ princípio apenas para melhorar meus relacionamentos, mas logo que comecei, percebi que poderia voltar ao mercado de trabalho e resolvi fazer o curso técnico" (ALUNA 1); "Em busca de estar sempre por dentro do conhecimento, buscar um bom emprego" (ALUNA 2) e "Continuei meus estudos com o intuito de conseguir uma melhor colocação no mercado de trabalho" (ALUNA 3).

Pelos depoimentos dados, percebe-se que todas procuram retomar os estudos em busca de melhores condições para concorrer a um bom emprego ou para garantir seu futuro. Depreende-se que a busca pelo conhecimento e profissionalização gira em torno da realização de sonhos e essa realização se dá pelas conquistas de bens materiais, por meio da colocação no mercado de trabalho. 
Perguntadas se encontraram dificuldades para retornar aos estudos, cinco (5) entrevistadas afirmaram que não encontraram dificuldades para voltar a estudar, apenas três (3) apresentaram restrições, tais como: "Tive problemas pessoais, devido à falta de tempo e dificuldade de memorizar as matérias" (ALUNA 1); "As dificuldades financeiras, pois para me manter não tenho ajuda de familiares. Tenho que trabalhar final de semana" (ALUNA 3); "Dificuldades no aprendizado" (ALUNA 5).

É perceptível, pelos depoimentos dados que as discentes culpabilizam-se pelo "fracasso escolar". Nesse sentido, Ferreira (2007, p. 83) denuncia,

É imprescindível, também que todos/as os/as jovens e homens e mulheres, entendam que não foram (e não são) os responsáveis pela descontinuidade de sua trajetória educacional. Cabe aos poderes públicos essa responsabilidade, que nunca priorizaram a educação como fator essencial para a dignidade humana.

Quando questionadas se houve resistência/impedimento por parte da família na volta à escola, apenas uma aluna enfrentou impedimento por parte da família e por parte do marido, como indica o depoimento a seguir: "Minha mãe falava que velho não pode estudar e que meu marido me impediu de voltar à escola" (ALUNA 2).

Neste contexto, observa-se que na ordem patriarcal imposta, o marido é o responsável em direcionar o destino da esposa, esse imaginário construído socialmente, encontra-se ainda presente na nossa realidade atual.

Historicamente a educação feminina, durante longo tempo, tanto na escola como na família, foi normatizada e controlada pelos homens e de acordo com que estes consideravam necessários e a inserção da mulher no processo educacional formal se deu mediante avanços e recuos, em lutas constantes com a ideologia patriarcal, com os poderes públicos e com as instituições religiosas.

$\mathrm{Na}$ discussão empreendida sobre a escolha do Curso Técnico Integrado de Segurança do Trabalho, observa-se, por meio dos relatos, que a motivação deu-se devido ao reconhecimento da qualidade do ensino gratuito do Ifes: "Para obter um ensino médio de boa qualidade e concluir já com um curso profissionalizante" (ALUNA 1); "Para obter o ensino médio e um técnico e assim ter uma chance maior no mercado de trabalho" (ALUNA 2); "Segurança do Trabalho foi o curso que me pareceu melhor no momento. E a oportunidade de ter um ensino médio de qualidade e gratuito, óbvio" (ALUNA 3).

Outra motivação apontada foi a existência de vagas que são ofertadas hoje para os profissionais em Segurança do Trabalho, pelo setor produtivo, como pode ser observado pelos relatos: "É um dos cursos que o mercado está mais aberto para emprego" (ALUNA 6) e outra depoente acrescenta:

"Eu estava no $2^{\circ}$ ano do ensino médio, quando decidi fazer um processo seletivo Ifes, pois é uma instituição que nos oferece uma educação de qualidade. O motivo maior foi o curso técnico, pois assim estou me capacitando para o mercado de trabalho" (ALUNA 8).

Apesar de a mulher estar cada vez mais presente no mercado de trabalho, movidas pela necessidade da manutenção da família, ou mesmo pela realização profissional, ainda há poucos espaços para o público feminino, em determinados setores da área industrial, prevalecendo à preferência de escolha pelo sexo masculino (FERREIRA, 2003).

Há de se ressaltar que os alunos formados em cursos de formação técnica ou tecnológica como os ofertados pelo Ifes, possuem maior possibilidade de conseguiram inserção no mercado de trabalho, conforme dados da própria instituição (LIRIO, 2009; MENDES, 2009).

Questionadas se continuarão os estudos ao terminar o PROEJA, 100\% das entrevistadas disseram que sim, e os cursos escolhidos são diversos, como gastronomia, engenharia, psicologia, serviço social dentre outros na área das Ciências Humanas.

A SIS, divulgada pelo IBGE (2010), aponta que dentre os alunos matriculados na EJA e que continuavam buscando a melhoria do seu nível educacional, $6,6 \%$ da proporção de $5,7 \%$ dos brasileiros entre 25 e 64 anos eram mulheres.

Outros dados levantados, nos mostram as colocações das depoentes sobre as expectativas que possuem sobre a inserção no mercado de trabalho: "Positiva, até porque o mercado necessita de nós Técnicos de Segurança do Trabalho para ajudá-los" (ALUNA 7); "Tenho a expectativa de que vou conseguir um bom emprego, pois me sinto capacidade e me dedico muito no curso e sei que serei uma ótima profissional, pois há quase 4 anos estou me preparando para isso" (ALUNA 8). E ainda: 
“Estou muito otimista, pois a barreira que julgava intransponível que é a idade, já pude observar que há uma abertura de mercado, o que é uma novidade quanto à área de atuação, creio que vou me adaptar muito bem porque estarei fazendo o que gosto" (ALUNA 1).

A partir dos relatos, depreende-se que as expectativas são positivas em relação à inserção no mercado de trabalho e apontam a importância da conclusão do ensino técnico para melhoria de vida pessoal e profissional.

\section{CONSIDERAÇÕES FINAIS}

Pode-se constatar, por meio dessa investigação, uma participação efetiva da mulher no Curso Técnico Integrado de Segurança do Trabalho. Percebe-se assim, como as mulheres estão, gradativamente, vencendo barreiras e buscando inserir-se no mercado de trabalho, em profissão que até pouco tempo era reduto masculino: atividades na área industrial.

Constatou-se também que público alvo do PROEJA vem se modificando, marcado principalmente pela juvenilização, caracterizado também pela não descontinuidade escolar, e que procuram o Programa como alternativa de elevar sua escolarização e profissionalização para inserir no mundo do trabalho, em melhores condições de competitividade.

Também se averiguou, pelos depoimentos das entrevistadas, que estas enfrentam condições adversas no seu cotidiano, persistindo ainda a desigualdade sexista nas relações escolares e familiares, que se traduzem ainda na subordinação da mulher ao homem. Foi comprovado, que as mesmas enfrentam dificuldades, em relação à família para estudarem e exercerem sua profissão, causadas pelo preconceito e por não terem assistência do poder público em relação ao atendimento à infância.

Estas constatações vêm confirmar a hipótese levantada de que as dificuldades enfrentadas pelas mulheres são de cunho histórico e cultural, porque a sociedade brasileira ainda apresenta uma mentalidade machista, herança do patriarcalismo, na qual defendia que o homem devia promover o sustento da casa e à mulher, caberia o cuidado da casa e dos filhos. Deve-se ainda destacar as barreiras enfrentadas como salários menores em relação aos homens e a dupla jornada de trabalho.

Nesta perspectiva, a elevação da escolaridade aliada à profissionalização desse público feminino, torna-se um requisito importante para a construção e reconstrução dos seus valores identitários, da sua percepção enquanto sujeitos transformadores da sociedade e para sua realização profissional.

Cada vez mais o gênero feminino está se conscientizando de que para se tornarem sujeitos plenos de cidadania, é importante o retorno e a continuidade do estudos para ingresso no mercado de trabalho e que esta escolarização, atrelada à formação profissional, irá permitir essa inserção de forma mais competitiva.

\section{REFERÊNCIAS}

BRASIL. Ministério da Educação, Secretaria de Educação Profissional e Tecnológica. Programa Nacional de Integração da Educação Profissional com a Educação Básica na Modalidade de Educação de Jovens e Adultos - PROEJA. Documento Base. 2007. Disponível em <http://portal.mec.gov.br/setec.> Acesso em: 21 jun. 2010.

BRUSCHINI, Maria Cristina Aranha; RICOLDI, Arlene Martinez. Articulação Trabalho e Família: Famílias de Baixa Renda e Políticas de Apoio às Trabalhadoras. São Paulo: Fundação Carlos Chagas/Departamento de Pesquisas Educacionais, 2008. Disponível em: <http://www.fcc.org.br/pesquisa/publicacoes/textos_fcc/arquivos/1436/arquivoAnexado.pdf>. Acesso em: 27 set. 2010.

FERREIRA, M. J. de Resende. A Inserção feminina na formação técnico-profissional: proposta de um programa estratégico para implementar sua participação nos Cursos de Mecânica e de Eletrotécnica do CEFETES. 2003, 151 f. Dissertação (Mestrado em Educação Profissional). Programa de Pós-Graduação em Educação do CEFET-ES. Vitória, 2003.

M. J. de Resende. Escolarização e gênero feminino. Um estudo de caso no EMJAT/CEFETES. 2007. 98 f. Monografia (Especialização). Curso de Especialização do Programa Nacional de Integração da Educação Profissional com a Educação Básica na Modalidade da Educação de Jovens e Adultos. CEFETES, Vitória, 2007.

M. J. de Resende. Por que é tão difícil frequentar a escola? Escolarização e gênero feminino no EMJAT/Cefetes. Cadernos ANPED, v. 01, p. 5-15, 2008.

FERREIRA, Eliza Bartolozzi; RAGGI, Désirré; RESENDE, Maria José. A EJA integrada à educação profissional no CEFET: avanços e contradições. Trabalho aprovado pelo GT 9, para a 30a REUNIÃO ANUAL DA ASSOCIAÇÃO NACIONAL DE PÓS-GRADUAÇÃO E PESQUISA EM EDUCAÇÃO (ANPED, 2007, Caxambu - MG. [Trabalho Apresentado] Minas Gerais, 2007. 1 CD -ROOM.

GOUVÊA, Gustavo. Salário das mulheres aumenta no Estado. A Tribuna, Vitória, 09 setembro 2010. Economia, p.29. 
IBGE. Ministério do Planejamento, Orçamento e Gestão. Síntese de Indicadores Sociais: Uma análise das condições de vida da população brasileira. 2009. Disponível em: < http://www.ibge.gov.br/home/estatistica/populacao/condicaodevida/ indicadoresminimos/sinteseindicsociais2009/indic_sociais2009.pdf>. Acesso em: 27 set. 2010.

Ministério do Planejamento, Orçamento e Gestão. SIS 2010: Mulheres mais escolarizadas são mães mais tarde e têm menos filhos. 2010. Disponivel em: <http://www.ibge.gov.br/home/presidencia/noticias/noticia_visualiza.php?id_noticia=1717\&id_pagina=1>. Acesso em: 27 set. 2010

LIRIO, Leessanny Carlesso dos Santos. O currículo realizado no curso de Segurança do Trabalho do IFES-Vitória: pistas para o fortalecimento das redes de relações solidárias. 2009. 205 f. Dissertação (Mestrado em Educação). Programa de Pós-Graduação em Educação do Centro Pedagógico da Universidade Federal do Espírito Santo. Vitória, 2009.

LOURO, Guacira Lopes. Gênero, sexualidade e Educação: uma perspectiva pós-estruturalista. Petrópolis/RJ:Vozes, 1997.

MENDES, Ester L. Barros. Qualidade de ensino: um estudo sobre as

representações sociais dos alunos e alunas do CEFET-ES. 2009. $116 \mathrm{f}$.

Dissertação (Mestrado em Educação) Programa de Pós-Graduação em

Educação, Universidade Federal do Espírito Santo, Vitória, 2009.

MENEZES, Cristiane Souza de. A participação feminina em turmas da Educação de Jovens e Adultos. 2005. V Colóquio Internacional Paulo Freire - Recife, setembro 2005. Disponível em: < http://www.paulofreire.org.br/pdf/comunicacoes_orais/f>. Acesso em: 25 mai. 2009.

NADER, Maria Beatriz. Mulher: do destino biológico ao destino social. 2.ed. Vitória: EDUFES/Centro de Ciências Humanas e Naturais, 2001.

OLIVEIRA, Edna Castro de. ; CEZARINO, Karla Ribeiro de Assis; SANTOS, Júlio de Souza. Sujeitos da Educação de Jovens e Adultos no PROEJA. In: XXIV Simpósio Brasileiro - III Congresso Interamericano de Política e Administração da Educação, 2009, Vitória. Direitos humanos e cidadania: desafios para as politicas e a gestão democrática da educação, 2009. v. 08. p. 01-12. Disponível em: <http://www.anpae.org.br/congressos_antigos/simposio2009/88.pdf>. Acesso em: 27 set. 2010.

PEREIRA, Luzia Ribeiro. De donzela Angelical e esposa dedicada a profissional da Educação: a presença do discurso religioso na formação da professora. 1996. 150f. Tese (Doutorado em História da Educação). USP (Faculdade de Educação), São Paulo, 1996.

PEREIRA, Andréia da Silva; MIGUEL, José Carlos. "Mulher não precisava estudar": relatos de vida e de violência simbólica. REVEJ@ - Revista de Educação de Jovens e Adultos, v. 2, n. 3, p. 1-100, dez. 2008.

RIDENTI, S. G. U. A desigualdade de gênero nas relações parentais: o exemplo da custódia dos filhos. In: ARILHA, M.; MEDRADO, B.; RIDENTI, S. G. U. (orgs.). Homens e Masculinidades: outras palavras. São Paulo: FCC, ed. 34, 1998. Capítulo 7: p. 163-184. Disponível em: < www.alb.com.br/anais14/Sem03/C03010.doc>. Acesso em: 15 jun. 2010.

SPONCHIADO, J.I. Docência e relações de gênero: um estudo de dissertações e teses defendidas em instituições brasileiras no período de 1981 a 1995. PUC, São Paulo, 1997. 